\title{
The Bloomberg Global Initiative to Reduce Tobacco Use
}

\author{
Jonathan M. Samet MD, MS, Heather Wipfli, MA ${ }^{(I)}$
}

$\mathbf{I}^{\mathrm{n} 2}$ 2006, New York City donated \$125 million towards ending the global tobacco epidemic. The timing of this extraordinary donation was appropriate; tobacco now kills nearly 5 million people a year or $14000 \mathrm{ev-}$ ery day. Tobacco use accounts for more than one in 10 adult deaths, approximately $70 \%$ of which now occur in developing countries. A total of 145 nations have now ratified the Framework Convention for Tobacco Control (FCTC) and the success of the FCTC needs to be assured. Even as the majority of nations in the world ratified the FCTC and thereby committed to implementing its provisions, their capacity to do so is often inadequate. To date, the global tobacco control movement has not had a presence in all countries and many nations that ratified the FCTC lack the capacity to move forward. A failure to do so, particularly in the face of likely opposition from the multinational tobacco companies, would be a potentially disastrous outcome of the FCTC process.

Consequently, the funding of the new Bloomberg Initiative was at a critical moment, and responsive to this global need. The core objective of the Initiative is to reverse the global epidemic of tobacco use by enhancing tobacco control and capacity for tobacco control throughout the world's low and middle income countries. A special emphasis is being placed on five developing countries, where more than half of the world's smokers live: China, India, Indonesia, Russia, and Bangladesh. The Initiative will also support tobacco control in Brazil, Egypt, Mexico, Pakistan, Philippines, Poland, Thailand, Turkey, Ukraine, and Vietnam, as well as other countries with a high burden of tobacco use and high potential for successful change. (Table I)

Five key partner institutions are involved in carrying out the Initiative: World Lung Foundation, Center for Tobacco Free Kids, the CDC Foundation, World Health Organization, and Johns Hopkins Bloomberg
Table I

Prevalence of tobacco consume in deVeloping COUNTRIES

Country Prevalence(\%)

\begin{tabular}{lc}
\hline Bangladesh & 40.8 \\
\hline Brazil & 17.6 \\
\hline Egypt & 28.8 \\
\hline Indonesia & 28.7 \\
\hline Pakistan & 16 \\
\hline Poland & 32 \\
\hline Thailand & 25.7 \\
\hline Ukraine & 31.8 \\
\hline China & 31.4 \\
\hline India & 31.7 \\
\hline Mexico & 8.8 \\
\hline Philippines & 24.1 \\
\hline Russian Federation & 35.1 \\
\hline Turkey & 31.2 \\
\hline Vietnam & 18.5
\end{tabular}

School of Public Health. The specific activities of each organization are outlined in Table II.

The work carried out under the Initiative supports four proven tobacco control interventions. These interventions include: 1) increasing tobacco prices and preventing smuggling; 2) changing the image of tobacco by banning direct and indirect advertising and by conducting hard-hitting anti-tobacco public education campaigns; 3) protecting nonsmokers from exposure to other people's smoke; and 4) helping smokers quit.

The Initiative will support the implementation of these interventions through four key components: supporting public sector efforts to implement key tobacco

(I) Johns Hopkins, Bloomberg School of Public Health. USA

Fecha de aceptado: 4 de abril de 2007 
Table I I

\section{Activities in the Bloomberg Global Initiative}

\begin{tabular}{ll}
\multicolumn{1}{c|}{ Organization } & \multicolumn{1}{c}{ Activities } \\
\hline World Lung Foundation & $\begin{array}{l}\text { - Implement grant programs to initiate in-country } \\
\text { tobacco control measures }\end{array}$ \\
$\begin{array}{ll}- \text { Create global resource center for effective anti-tobacco } \\
\text { advertisements } \\
\text { - Support measures to prevent tobacco smuggling } \\
\text { - Operate Regional Center on tobacco control }\end{array}$ \\
\hline Campaign for Tobacco Free Kids & $\begin{array}{l}\text { Create a Global Advocacy Center } \\
\text { - Implement grant programs to support in-country tobacco control advocacy }\end{array}$ \\
\hline World Health Organization & $\begin{array}{l}\text { Provide global, regional, and in-country leadership in tobacco control } \\
\text { - Monitor global tobacco control policy implementation at country level }\end{array}$ \\
\hline CDC Foundation & $\begin{array}{l}\text { - Measure the current burden of tobacco and status of tobacco control in high burden } \\
\text { low income and middle income countries through creation of a global adult tobacco survey }\end{array}$ \\
\hline Johns Hopkins Bloomberg School of Public Health & $\begin{array}{l}\text { - Expand training and economic studies, with particular focus on China } \\
\text { - Analyze, refine and optimize tobacco control interventions }\end{array}$
\end{tabular}

control interventions, supporting advocates' efforts to educate communities and to encourage policy change, rigorously monitoring the status of global tobacco use and countries' progress implementing key interventions, and optimizing tobacco control interventions.

A core element of the Initiative is a competitively awarded Grants Program to support projects to develop and deliver high-impact tobacco control interventions. This funding is being made available to organizations that can work at the country level on one or more of the Initiative's four strategic components. The grants program is managed by two of the partner organizations - the World Lung Foundation through the International Union Against Lung Disease and the Campaign for Tobacco-Free Kids.

Governments, state/provincial authorities, and non-governmental organizations (NGOs) from lowand middle-income countries are eligible to apply for grants. The Initiative places priority on grants from the target countries, however, applicants from nonBloomberg countries may also apply for grants. The grants program is not designed to fund basic research, academic studies, prevalence surveys or cessation services (unless they are integral to a policy initiative). The grants program is seeking projects that lead to substantial, sustainable improvements in tobacco control laws, regulations, policies and programs, including (but not restricted to):
- $\quad$ Tax and price measures, including anti-smuggling measures;

- Establishment of smoke-free workplaces and public places, and effective enforcement of smoke-free policies;

- Direct and indirect advertising bans;

- Other evidence-based regulatory/legislative initiatives; and

- Effective, long-term mass media campaigns and programs targeting the general population and sub-population groups.

In response to the launch of the Grants Program on 1 December 2006, a wide range of governments and NGOs from 68 countries submitted 588 Project Ideas. In early February 2007, 102 invitations to develop full proposals due by 19 March were issued to governments and NGOs in 33 countries: Argentina, Bangladesh, Brazil, Cambodia, China, Czech Republic, Egypt, Georgia, Guatemala, Honduras, India, Indonesia, Kazakhstan, Kyrgyzstan, Laos, Mexico, Mongolia, Nepal, Niger, Nigeria, Pakistan, Paraguay, Philippines, Poland, Romania, Russia, Sri Lanka, Tanzania, Thailand, Uganda, Ukraine, Uruguay, and Vietnam. The deadline for submission of Project Ideas for the second round of grants is 13 June.

In between the formal grant rounds, applications for Rapid Response Grants of up to US\$50,000 will also be con- 
sidered. These grants will help meet unanticipated needs where there are identifiable benefits associated with rapid funding. Additional information regarding the grants can be found at www.tobaccocontrolgrants.org.

In addition to supporting country-level grants, the Initiative is undertaking systematic surveys of adult prevalence. While many individual countries have surveys to monitor adult tobacco use, there is no standard global adult tobacco survey that consistently tracks prevalence (cigarette smoking and other tobacco use), exposure to secondhand smoke, cessation, risk perceptions, knowledge and attitudes, exposure to media and price and taxation issues, which are critical measures for tobacco control programs and policy development. To fill this gap the CDC Foundation, in collaboration with the WHO and the Johns Hopkins Bloomberg School of Public Health, is establishing a Global Adult Tobacco Survey (GATS). GATS will become a new component of the CDC's ongoing Global Tobacco Surveillance System (GTSS) which comprises the Global Youth Tobacco Survey (GYTS), the Global School Personnel Survey (GSPS) and the Global Health Profession Students Survey (GHPSS).

Other major activities being undertaken by the Initiative include the establishment of a global resources center for effective counter-advertisements, a global advocacy resource center including resources for advocacy and legal support (www.tobaccofreecenter.org), and a number of new training opportunities in tobacco control and project management. The initiative is also assisting in building greater human resource capacity for tobacco control by supporting additional WHO country-level staff and by providing staff in new regional centers for tobacco control. The Regional Centers in China and India are already operational.

The Bloomberg Initiative represents a major new source of resources and energy in tobacco control. A number of new professionals are being brought into the tobacco control field thanks to the initiative and activities unthinkable only a year ago are now quickly becoming a reality. In the end, however, the success of the Bloomberg Initiative will not only be judged on the capacity built, but on how many lives were saved. For this reason, the Initiative's focus on high-impact interventions and key policy changes in high burden countries provide the greatest hope for significant shifts in global tobacco-related death and disease trends in the coming decade. 